\title{
Demethylation of Quinine Using Anhydrous Aluminium Trichloride
}

\author{
Aiyi Asnawi, As'ari Nawawi, Rahmana Emran Kartasasmita \& Slamet Ibrahim \\ School of Pharmacy, ITB Bandung \\ J1. Ganesha No. 10 Bandung, Jawa Barat-Indonesia \\ Email: aiyiasnawi@students.itb.ac.id
}

\begin{abstract}
Quinine is a natural alkaloid having a methoxy group bound to quinoline ring and an allyl group bound to quinuclidine ring. Demethylation of quinine applying strong acid such as $\mathrm{HBr}$ or $\mathrm{HI}$ at high temperature was unsuccessful. The aim of this research was to obtain demethylated quinine by means of mild and selective demethylation procedure to prevent the addition reaction of allyl group. Selective demethylation of quinine has been carried out using anhydrous aluminium trichloride as reagent. The demethylation product was achieved in $68.12 \%$ yield by mole ratio of quinine to anhydrous aluminium trichloride of 1 to 4 in dried methylene chloride under nitrogen atmosphere. The reaction was firstly carried out at $0^{\circ} \mathrm{C}$ for $4 \mathrm{~h}$ and after the reaction mixture reached room temperature, the reaction was continued up to $24 \mathrm{~h}$.
\end{abstract}

Keywords: aluminium trichloride; demethylation; methylene chloride; quinine.

\section{$1 \quad$ Introduction}

Quinine is an alkaloid obtained from the bark of cinchona tree. It is a levorotatory diastereomer of quinidine. Quinine is used for the treatment of malaria, the prevention of nocturnal leg cramps, and the reversal of multidrug resistance during chemotherapy [1].

In the last two decades, cinchona alkaloids have gained very interest because of their successful applications in asymmetric synthesis [2]. For their prominent role as chiral bases, ligands, phase-transfer catalysts, and surface modifiers, they were even considered as belonging to a privileged catalyst class [3]. The most often used selective synthetic modifications of cinchona alkaloids were based on the replacement of C-9 hydroxy group by other functionalities, including those with nitrogen [4] and halogen [5].

A variety of combination systems of a hard Lewis acid and a thiol or a sulfide functional groups as a soft nucleophile have been developed for $\mathrm{C}-\mathrm{O}$ bond cleavages of methyl ethers, benzyl ethers, esters, and lactones. In principle, it is possible with these systems to cleave a specific $\mathrm{C}-\mathrm{O}$ bond in the presence of other type of $\mathrm{C}-\mathrm{O}$ bond by shifting the balance between a Lewis acid and a soft

Received March $26^{\text {th }}, 2010$, Revised July $15^{\text {th }}, 2010$, Accepted for publication September $2^{\text {nd }}, 2010$. 
nucleophile [6]. Aluminium trichloride is well known as a Lewis acid, it can avoid the addition reaction to the double bound. However, this selectivity is not easily obtained and depends on the nature of the different functions handled by the ligand. Thus, the choice of reagent capable of cleaving the methyl aryl ether bound is very important. Many agents of O-demethylation of ethers mostly in the homogenous phase have been reported. They are classified as Bronstead acid such as hydrogen halogen, pyridine, amine salts (pyridinium chlorydrate and bromhydrate) or as Lewis acids [7-9].

In the present paper, we report demethylation of quinine under relatively mild conditions using anhydrous aluminium trichloride. The early attempts to prepare demethylation of quinidine (one of cinchona alkaloids) using hot concentrated mineral acids were unsuccessful and demethylation of quinine using boron tribromide at $-78^{\circ} \mathrm{C}$ for $24 \mathrm{~h}$ has been reported [10]. According to the literature search, this is the first report on demethylation of quinine using anhydrous aluminium trichloride. The demethylated quinine product would be used as novel chiral base reagent for separation of racemic mixture by means of diastereomic salt formation.

\section{Experimental}

\subsection{General}

The reaction was carried out in oven-dried glassware with magnetic stirrer and performed under nitrogen atmosphere in dried solvents. ${ }^{1} \mathrm{H}$ and ${ }^{13} \mathrm{C}$ NMR spectra (400 and $100.6 \mathrm{MHz}$, repectively) were recorded on a JEOL JNM-LA 400 spectrometer using $\mathrm{Me}_{4} \mathrm{Si}$ as the internal standars $(0 \mathrm{ppm})$. IR spectra were measured with a FTIR Jasco-4200 spectrophotometer. For HPLC analysis, a Perkin-Elmer PE 200 binary pump was used. A Perkin-Elmer SCIEX (Concord, ON, Canada) API 150 MCA mass spectrometer equipped with a Turbo ion interface was used.

\subsection{Materials}

Aluminium trichloride was obtained from Fluka, quinine was obtained from PT Sinkona Indonesia Lestari. Thin-Layer Chromatography (TLC) was carried out on Merck-25 TLC aluminium sheets silica gel 60 F254. The other reagents and solvents (ACS certified grade) were used without further purification.

\subsection{Demethylation of Quinine}

Quinine 1 (3.24 g, $10 \mathrm{mmol})$ was dissolved in $50 \mathrm{~mL}$ of methylene chloride and cooled to $0^{\circ} \mathrm{C}$ (Ice/ $/ \mathrm{NaCl}$ bath) under nitrogen atmosphere. Aluminium trichloride $(40 \mathrm{mmol})$ in $50 \mathrm{ml}$ of methylene chloride was then added drop wise 
to the stirred solution for $4 \mathrm{~h}$. After the reaction mixture reached room temperature, the mixture was further stirred up to $48 \mathrm{~h}$. Water was carefully added to decompose excess aluminium trichloride. The reaction mixture was transferred into a separating funnel and after adjusting the aqueous phase with 1 $\mathrm{N}$ sodium hydroxide to $\mathrm{pH}$ of 11-12, the mixture was then shaked. The organic phase was discarded and the aqueous phase was re-adjusted with $1 \mathrm{~N}$ hydrochloric acid to $\mathrm{pH}$ of $8-9$ which affords precipitation. The precipitate was dissolved in methylene chloride, dried over anhydrous sodium sulphate and dried in vacuum to dryness.

\section{$3 \quad$ Results and Disscusion}

The plausible mechanism of demethylation of $\mathbf{1}$ is proposed in Figure 1. The initial complexation of the basic quinoline $\mathrm{N}$ atom, quinuclidine bicyclic $\mathrm{N}$ atom and the ethereal oxygen atom in $\mathbf{1}$ by aluminum trichloride is followed by elimination of chloride from the resultant complex to generate a chloride salt $\mathbf{2}$. The Al-quinolinium cation of $\mathbf{2}$ is expected to be highly reactive in a nucleophilic displacement reaction at the methoxy position in which chloride acting as a nucleophile. This reaction step produces methylchloride and a Alquinolinimine $\mathbf{3}$. The Al-quinolinimine $\mathbf{3}$ then occur hydrolysis to complete demethylation of quinine to generate 4 .

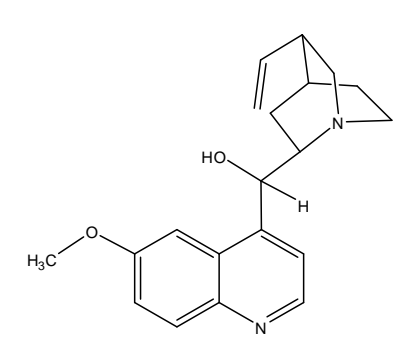

(1)

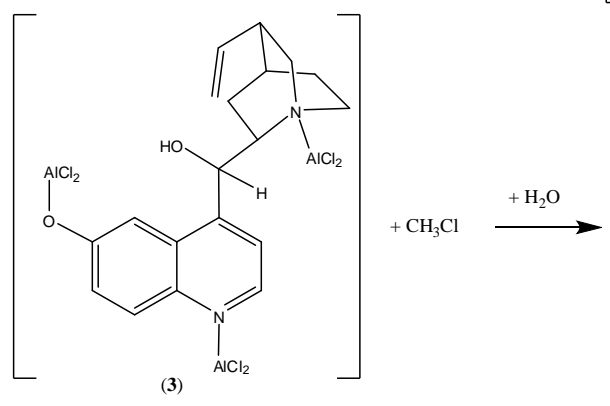

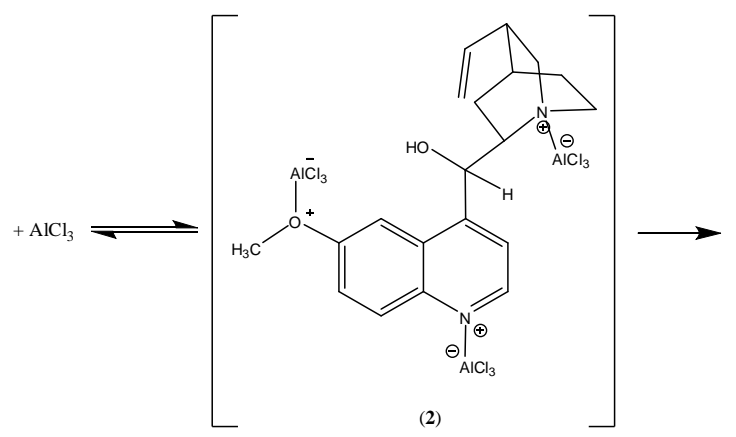

(2)

Figure 1 Mechanism of demethylation of quinine 
The demethylation of $\mathbf{1}$ was greatly affected by the ratio of starting material. We examinated the demethylation reaction of $\mathbf{1}$ with several difference ratio of $\mathrm{AlCl}_{3}$ in methylene chloride and the results are summarized in Table 1. Treatment of 1 with 1 equivalent of aluminium trichloride for 4 hours gave no product and then reaction was continued for overnight but no any product was found (Run 1). Treatment of 1 with 3 equivalent of aluminium trichloride for 48 hours was $\mathrm{O}$-demethylated product $\mathbf{4}$ was obtained in a poor yield with a large amount of starting material 1 recovered (Run 2). Treatment of 1 with 4 equivalent of $\mathrm{AlCl}_{3}$ for 24 hours gave an O-demethylated product 4 in $68.12 \%$ yield (Run 3). Demethylation of quinine using boron tribromide was prepared in $60 \%$ yield [10].

Table 1 Mole ratio of reactants, condition and yield of demethylation of quinine.

\begin{tabular}{cccccccc}
\hline Run & $\begin{array}{c}\text { Quinine, } \\
\text { mole }\end{array}$ & $\begin{array}{c}\text { Aluminium } \\
\text { trichloride, } \\
\text { mole }\end{array}$ & Conditions & $\begin{array}{c}\text { Yield of } \\
\mathbf{4}\end{array}$ & $\begin{array}{c}\text { Analysis (\%) } \\
\text { Calcd, } \\
(\text { found) }\end{array}$ & $\mathbf{R f}^{\mathbf{b}}$ & $\begin{array}{c}\text { Mp. } \\
\left({ }^{\mathbf{0}} \mathbf{C}\right)\end{array}$ \\
\hline 1 & 1 & 1 & $\begin{array}{c}0^{\circ} \mathrm{C}, 4 \mathrm{~h} \text { up } \\
\text { to } 24 \mathrm{~h}\end{array}$ & nd & - & - & - \\
2 & 1 & 3 & $0^{\circ} \mathrm{C}, 48 \mathrm{~h}$ & Poor & - & - & - \\
& & & & & $\mathrm{C}, 68.41$ & & \\
3 & 1 & 4 & $0^{\circ} \mathrm{C}, 48 \mathrm{~h}$ & $68.12 \%$ & $\begin{array}{c}(68.96) \\
\mathrm{H}, 7.25(7.30) ;\end{array}$ & 0.15 & $160-$ \\
& & & & & $\mathrm{N}, 8.39(8.24)$ & & \\
\hline
\end{tabular}

Note:

nd $=$ not found any product of 4

${ }^{a}$ Elemental analysis of $\mathrm{C}_{19} \mathrm{H}_{22} \mathrm{~N}_{2} \mathrm{O}_{2} \cdot 1.3 \mathrm{H}_{2} \mathrm{O}$

${ }^{\mathrm{b}} \mathrm{TLC}$ on Silica gel; mobile phase: $\mathrm{MeOH}-\mathrm{CHCl}_{3}=1: 10$

It was found that 4 equivalent of the anhydrous aluminium trichloride are necessary to produce $\mathbf{4}$ in good yield.

From the IR spectra (Figure 2), it was found that the absorption peak intensity of hydroxyl group at wave number of $3367.1 \mathrm{~cm}^{-1}$ broaded with increasing of hydroxyl group, whereas the absorption peak intensity of - $\mathrm{CH}-$ group at wave number of $2923-2854 \mathrm{~cm}^{-1}$ decreased with the loss of the methyl of methoxy group during the reaction. 
Demethylation of Quinine Using Anhydrous Aluminium Trichloride 47

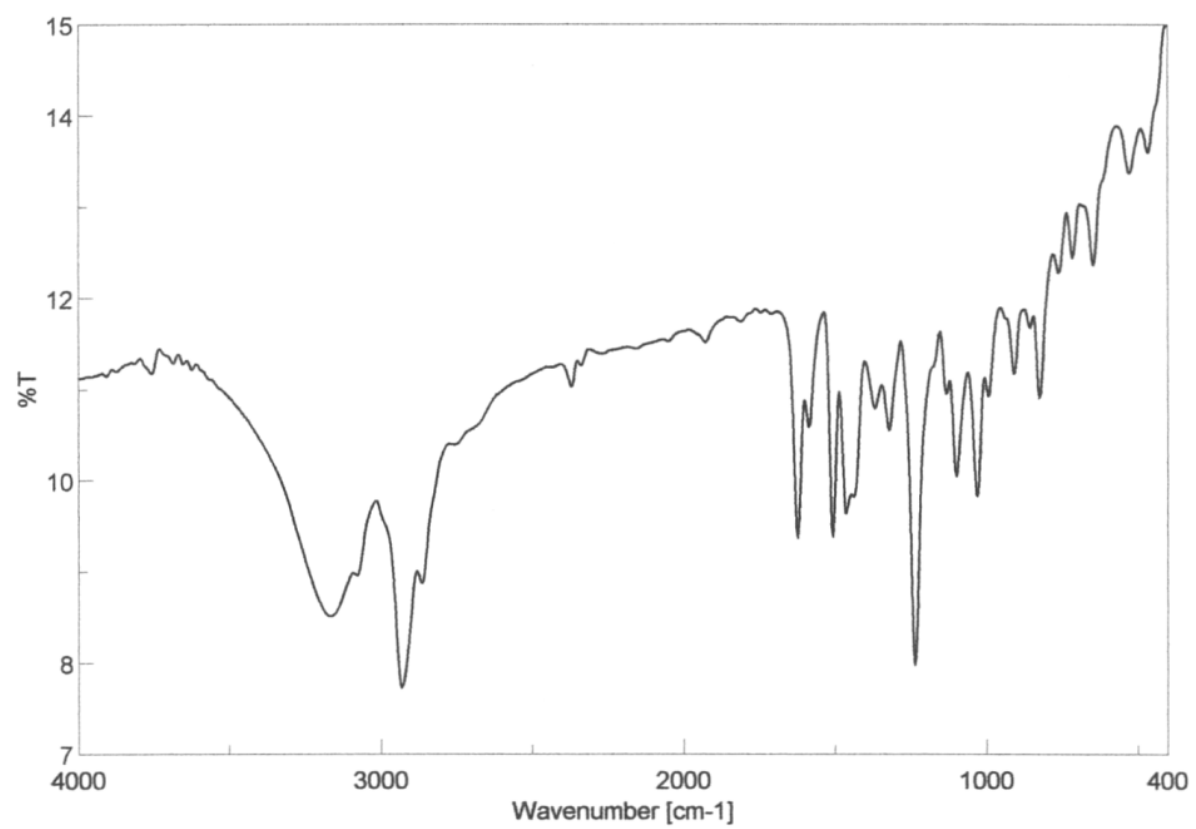

(a)

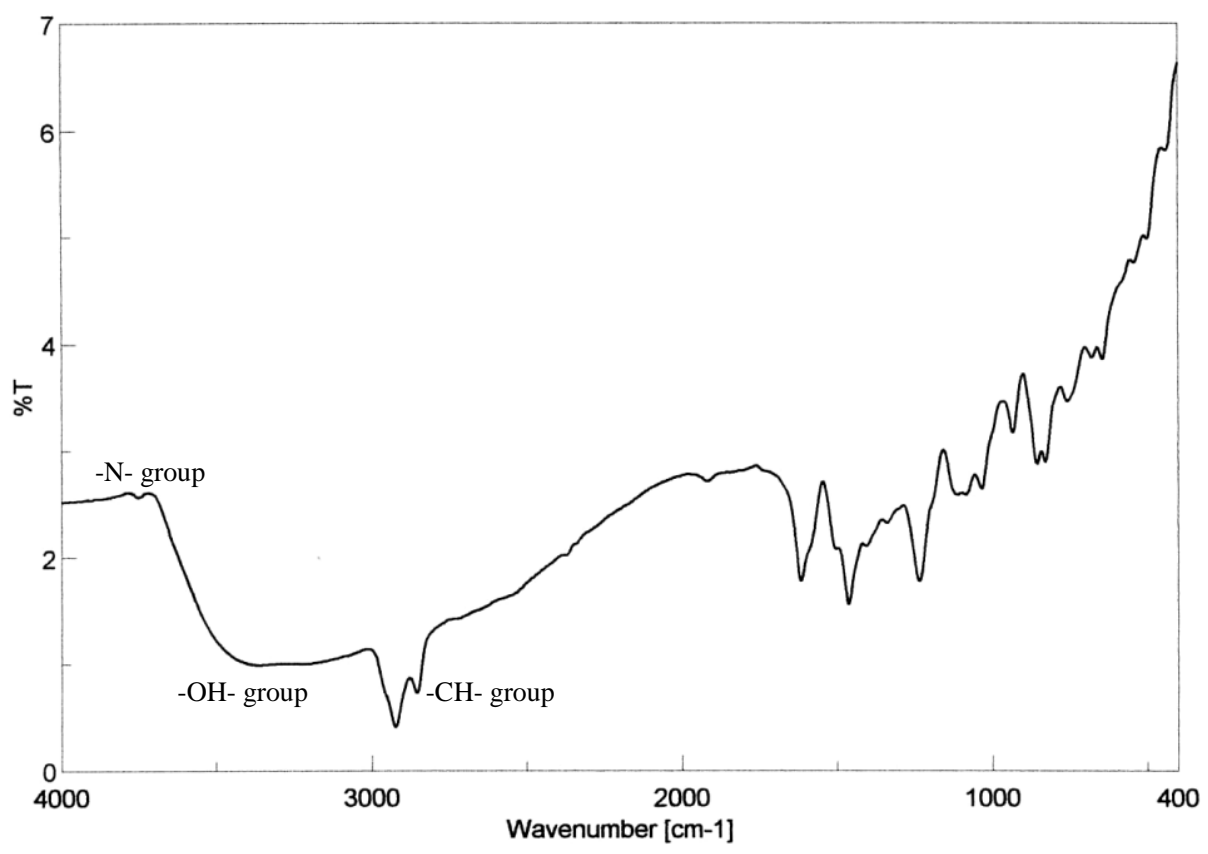

(b)

Figure 2 FT-IR spectra of (a) quinine, and (b) O-demethylatedquinine. 


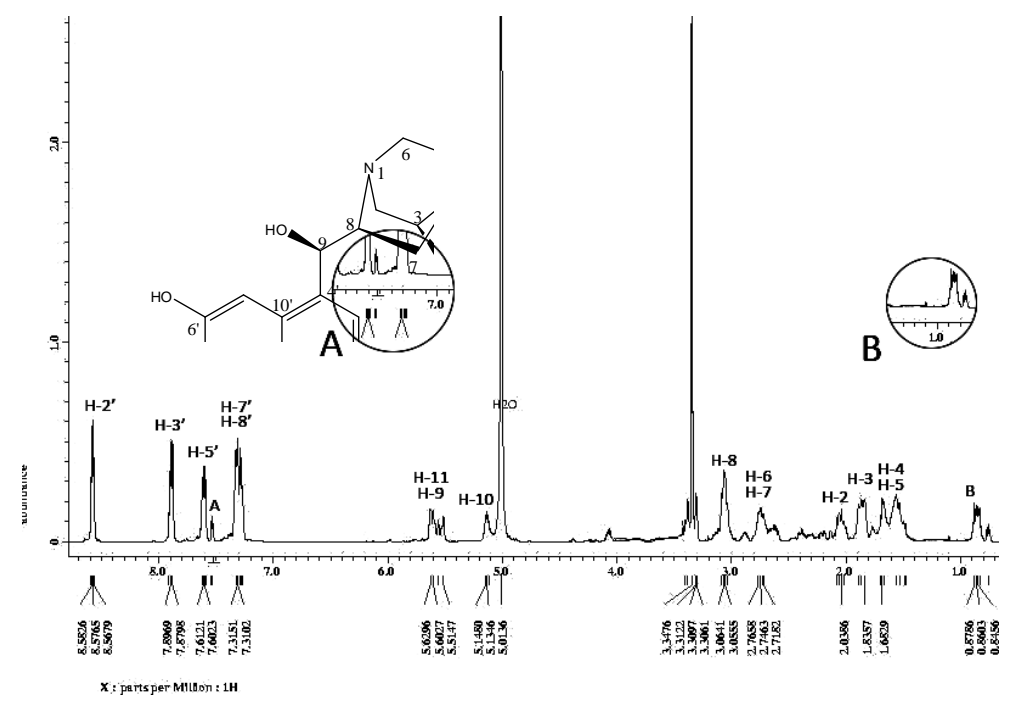

Figure $3{ }^{1} \mathrm{H}-\mathrm{NMR}$ spectra of O-demethylatedquinine (in $\mathrm{CD}_{3} \mathrm{OD}$; $\mathrm{A}$ and $\mathrm{B}$ are impurities).

Table 2 Chemical shift of proton and carbon resonances of O-demethylated quinine.

\begin{tabular}{|c|c|c|c|}
\hline Proton $^{a}$ & ${ }^{1}$ H-NMR ( $\delta$ ) & Carbon $^{\mathrm{b}}$ & ${ }^{13} \mathrm{C}-\mathrm{NMR}(\delta)$ \\
\hline $\mathrm{H}-2$ & $2.01(\mathrm{~m}, 2 \mathrm{H})$ & $\mathrm{C}-2$ & 60.14 \\
\hline $\mathrm{H}-3$ & $1.86(\mathrm{~m}, 1 \mathrm{H})$ & C-3 & 45.07 \\
\hline $\mathrm{H}-4$ & $1.83(\mathrm{~m}, 1 \mathrm{H})$ & C-4 & 34.46 \\
\hline H-5 & $1.68(\mathrm{~m}, 2 \mathrm{H})$ & C-5 & 30.83 \\
\hline H-6 & $2.71(\mathrm{~m}, 2 \mathrm{H})$ & C-6 & 58.18 \\
\hline H-7 & $2.74(\mathrm{~m}, 2 \mathrm{H})$ & C-7 & 28.32 \\
\hline $\mathrm{H}-8$ & $3.06(\mathrm{~m}, 1 \mathrm{H})$ & C-8 & 71.90 \\
\hline H-9 & $5.60(\mathrm{dq}, 1 \mathrm{H})$ & C-9 & 105.29 \\
\hline $\mathrm{H}-10$ & $5.14(\mathrm{t}, 1 \mathrm{H})$ & $\mathrm{C}-10$ & 140.68 \\
\hline $\mathrm{H}-11$ & $5.55(\mathrm{~m}, 1 \mathrm{H})$ & C-11 & 119.79 \\
\hline H-2' & $8.58(\mathrm{~d}, 1 \mathrm{H})$ & C-2' & 147.47 \\
\hline H-3' & $7.89(\mathrm{~d}, 1 \mathrm{H})$ & C-3' & 120.00 \\
\hline $\mathrm{H}-5$, & $7.61(\mathrm{dd}, 1 \mathrm{H})$ & C-4' & 149.73 \\
\hline H-7' & $7.28(\mathrm{~d}, 1 \mathrm{H})$ & C-5' & 116.18 \\
\hline \multirow[t]{5}{*}{$\mathrm{H}-8^{\prime}$} & $7.32(\mathrm{~d}, 1 \mathrm{H})$ & C-6' & 158.07 \\
\hline & & C-7' & 123.47 \\
\hline & & C-8, & 131.53 \\
\hline & & C-9' & 143.93 \\
\hline & & C-10' & 128.35 \\
\hline
\end{tabular}

${ }^{\mathrm{a}}$ Spectrum in $\mathrm{CD}_{3} \mathrm{OD} ; 400 \mathrm{MHz}$

${ }^{\mathrm{b}}$ Spectrum in $\mathrm{CD}_{3} \mathrm{OD} ; 100.6 \mathrm{MHz}$ 
The ${ }^{1} \mathrm{H}$ NMR spectra of (4) showed the disappearance of the methyl signals at $3.93 \mathrm{ppm}$, indicating the loss of the methyl of methoxy group during the reaction.
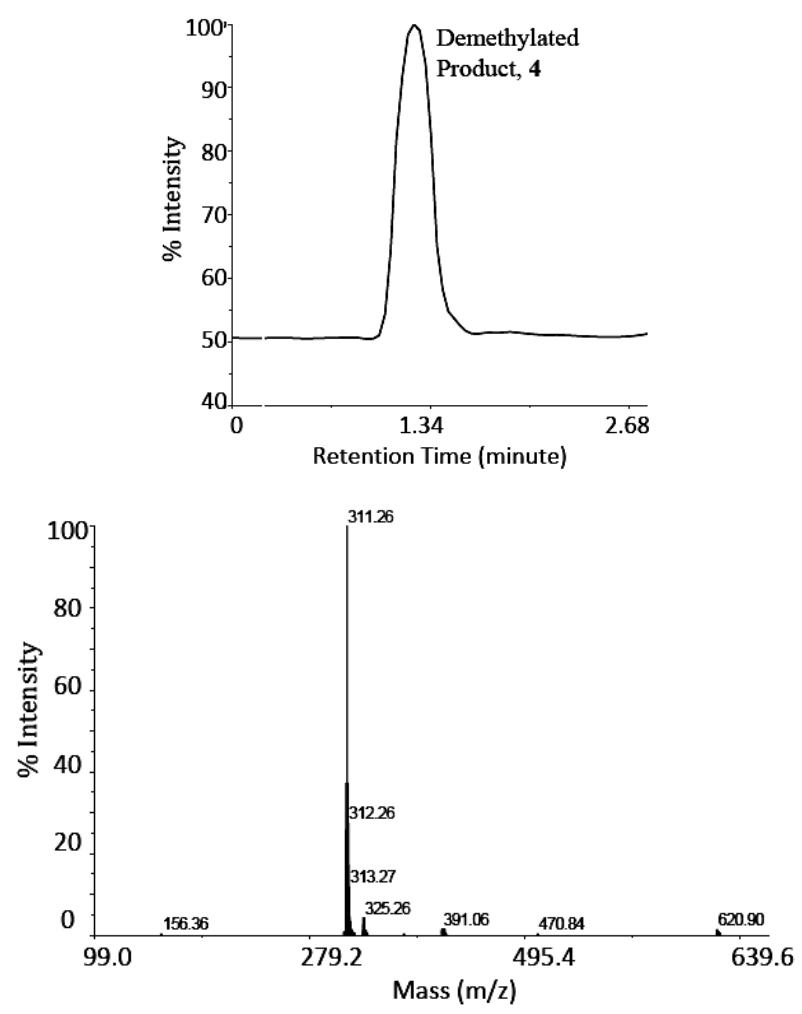

Figure 4 Chromatogram and mass spectrum of O-demethylated quinine (LCMS-ESI positive mode; injection volume: $20 \mu \mathrm{L}$, flowrate: $1 \mathrm{~mL} / \mathrm{min}$, mobile phase: methanol-water $=80: 20, \mathrm{v} / \mathrm{v}$ )

Liquid chromatographic-mass spectrometry-electro spray ionization (LCMSESI) was applied to determine the molecular weight of the demethylated product. The chromatogram showed only a single peak and its mass spectrum showed a persist peak with the mass of 311.26 (Figure 4). This $\mathrm{m} / \mathrm{z}(\mathrm{M}+1)$ was identical with the molecular weight of $\mathbf{4}$ (310.39). This result confirmed that the product contains 4 . However, some weak signals which have no relation to $\mathrm{H}$ atoms of $\mathbf{4}$ appeared in the ${ }^{1} \mathrm{H}-\mathrm{NMR}$ spectrum of the product, indicating the presence of impurities in the product. All efforts to purify the product were unfortunately unsuccessful. Consequently the differences in elemental analysis result of the product for $\mathrm{C}, \mathrm{H}$ and $\mathrm{N}$ were more than $0.5 \%$ between calculated and measured results. 


\section{Conclusions}

4-((R)-Hydroxy $((2 S, 4 S, 8 R)-8$-vinylquinuclidin-2-yl)methyl)quinolin-6-ol was successfully synthesized by demethylation of quinine under mild condition applying aluminium trichloride as reagent with the yield of $68.12 \%$. The presence of impurities in the final product needs a further purification to obtain high purity for its application as reagent for stereoselective reaction.

\section{Acknowledgement}

The authors greatefully acknowledge funding support from the Riset KK ITB under the institute of research-LPPM, Institut Teknolgi Bandung with Contract No. 010D/K01.15/PL/2009.

\section{References}

[1] Honigsbaum, M., The fever trail. The hunt for the cure for malaria, London, Macmillan, 30, 2001.

[2] Yoon, T.P. \& Jacobsen, E.N., Privileged Chiral Catalysts, Science, 299(5613), pp. 1691-1693, 2003.

[3] Vakulya, B., Varga S, Csámpai A. \& Soos, T., Highly Enantioselective Conjugate Addition of Nitromethane to Chalcones Using Bifunctional Cinchona Organocatalysts, Org. Lett., 7(10), pp. 1967-1969, 2005.

[4] Braje, W.M., Wartchow, R. \& Hoffmann, H.M.R., Structure and Mechanism in Cinchona Alkaloid Chemistry: Overturning a 50-Year-Old Misconception, Angew. Chem. Int. Ed., 38(17), pp. 2539, 1999.

[5] Zielin'ska-Błajet, M., Siedlecka, R. \& Skarzewski, J., Chiral phenylselenyl derivatives of pyrrolidine and Cinchona alkaloids: nitrogen-selenium donating ligands in palladium-catalyzed asymmetric allylic alkylation, Tetrahedron, Asymmetry, 18, pp. 131-136, 2007.

[6] Node, M., Hao, X.-J., Nishide, K., \& Fuji, K., A formal asymmetric synthesis of Calabar bean alkaloids, Chemical and Pharmaceutical Bulletin, 44(4), pp. 715-719, 1986.

[7] Larock, R.C., Comprehensive Organic Transformations, VCH. Publishers, Inc. New York, pp. 501-504, 1989.

[8] Burwell, R.L. Jr., The Cleavage of Ethers, Chem. Rev., 54, pp. 615-685, 1954.

[9] Gerrard, W. and Lappert, M. F., Reactions Of Boron Trichloride With Organic Compounds, Chem. Rev., 58(6), pp. 1081-1111, 1958.

[10] Aruzo, H.D., Cook, J.M. and Christie, D.J., Synthesis of 10,11Dihydroxydihydroquinidine N-Oxide, A New Metabolite of Quinidine, Journal of Natural Product, 53(1), pp. 112-124, 1990. 